\title{
Notes on the Maramureş Dialect
}

An exact phonetic transcription of the spoken dialect would be overladen with diacritic marks that, for typographical reasons, have had to be omitted. Translation of the dialect into literary Romanian, however, would result in a significant distortion of the "texts," altering the rhymes, rhythms, nuances, and oral compositional subtleties. For the sake of clarity for the general reader, as well as representativeness of the oral tradition, I have chosen a mode of transcription that may be considered an adequate compromise: it retains basic features of the spoken dialect while simplifying the representational form. To this end, I wish to thank Dr. Prof. Mihai Pop, Magdalena Vulpe, and Ioană and Mihai Dăncuş for their generous assistance, as well as acknowledging Iuliana Balea of Ieud and Professor Ronelle Alexander of Berkeley for their contributions.

There is considerable variation from one village to another; hence, the transcription adheres to the grai, or speech, of Ieud. Pronunciation also differs within the village; this difference tends to be accentuated between the generations. The following points should be noted in reading the texts:

1. In Maramures, there is a tendency to eliminate the final syllable of verb forms, of vocative forms of proper names (e.g., Ştefan = $\widehat{S} t e$ ), of the preposition fără (without), which becomes făr. As is general in spoken Romanian, the consonants $l$ and $n$ in final position are frequently dropped: $d r u m u l=d r u m u ;$ nimen $=$ nime . 
2. All pronouns have been written with $i$ preceding $e$ because of the colloquial pronunciation; this is not specific to Maramures but is a general phenomenon: $e l=i e l$.

3. In Maramureş, the phonetic distinction between the reflexive particle se and the future particle să has been lost. As a rule, se is pronounced as să. Similarly, the preposition pe is pronounced as $p \check{a} ;$ de $p e=d i$ pä; dece $=$ diptce. Also, aşa is pronounced as aşă or ăşe, depending on the rhyme.

4. The consonants $m, n, l, t$ are palatalized in position before $i$ or $e: n^{\prime} e$ as in bin'e; in the case of $m+i=m n^{\prime} i$, for example, mire $=$ mnire. Also, $t$ and $d$ followed by $e$ or $i$ are pronounced as soft sounds.

5. The final $i$ of the plural forms of names and of second person verb forms is not pronounced after $s, z, s, t$.

6. Şi becomes şi except when followed by $i$, for example, şi $m$-am dus, şi ieu.

7. The following correspondences are relatively constant:

\begin{tabular}{ccl} 
Standard Romanian & Dialect & \multicolumn{1}{c}{ Examples } \\
$v$ & $z$ & vin = zin \\
$f$ & $s$ & fin $=$ sin \\
ch/e & $t$ & chemat $=$ temat \\
gh/e & $d$ & gheaţa deata \\
$j / o, u$ & $g i$ & joc $=$ gioc \\
$p / i$ & pti & picior $=p t i c i o r$ \\
$b / i$ & bdi & bietu $=$ bdietu
\end{tabular}

8. Regarding pronunciation of vowels:

All accented $e$ are more open than the normal Romanian $e$, as is the accented diphthong $e a$ in final position, for example, mea $=$ me.

The diphthong $o a$ is pronounced as an open $o$, for example, doarme $=$ dorme .

For further detail on the Maramureş dialect, see Vulpe 1984. 